\title{
Study on the Effect of Continuity and Load Angle of Prefabricated Cross-Flaws on Crack Initiation and Coalescence
}

\author{
Dongxu Liang $\mathbb{C D}^{1,2}$ Nong Zhang $\mathbb{i D}^{1,2}$ and Haoyu Rong $\mathbb{D}^{1,2}$ \\ ${ }^{1}$ Key Laboratory of Deep Coal Resource Mining, Ministry of Education of China, Beijing, China \\ ${ }^{2}$ School of Mines, China University of Mining and Technology, Xuzhou, Jiangsu 221116, China \\ Correspondence should be addressed to Nong Zhang; zhangnong@cumt.edu.cn
}

Received 12 April 2021; Accepted 27 July 2021; Published 5 August 2021

Academic Editor: Chengzhi Shi

Copyright (C) 2021 Dongxu Liang et al. This is an open access article distributed under the Creative Commons Attribution License, which permits unrestricted use, distribution, and reproduction in any medium, provided the original work is properly cited.

In this study, a model that is closer to the state of fracture presentation in natural rocks has been developed, which is different from the previous. The cross-flaws can be characterized by the joint persistency $(k)$ and the angle between the primary flaws and axial load $(\alpha)$. The two parameters were varied individually and, by combining them, nine specimens with different nodal parameters were formed. Laboratory specimens and numerical simulations were performed on these specimens to investigate the crack extension process and the variation of crack initiation and coalescence stresses. It is found that a new category of crack coalescence is discovered according to the experimental results besides those reported before, and the angle $\alpha$ affects whether tensile-shear cracks appear. Also, $\alpha$ has an impact on the location where crack first occurs. The joint persistency $k$ alters rock failure mode and has a substantial effect on crack initiation stress. However, the effect on the aggregation stress is not significant. The crack initiation stress decreases in the case of cross-flaws in contrast to flat fissures. In addition, the flat-joint model in PFC2D is used for numerical simulation. It is possible to conduct a study that is difficult to achieve experimentally by using simulations, i.e., only changing one macroparameter without changing others and thus studying the changes in the effect on cracking during fracture. The simulation results are in good agreement with the experimental results. At the same time, the connection mode and the width of the crack coalescence zone of the primary defect, which is difficult to observe in the experiment, are found out from the numerical simulation.

\section{Introduction}

Flaws such as faults and joints presenting in rocks are common and are an important parameter for rock engineering designers to consider. For underground engineering, it is also of great significance to the stability of the support system. Especially in coal mines, anchoring the jointed rock mass is very extensive. Dynamic ground support in underground mines is used to stop the deformation and damage of the surrounding rock and to reinforce the rock mass by means of support elements. However, the deformation of the rock mass is often accompanied by the expansion of cracks leading to the effectiveness of the surrounding rock strength and the study of the development of rock cracks becomes very important for the support members to carry out how to effectively stop the deformation of the surrounding rock. It is valuable to investigate the main expansion mode of rock fracture and main fracture types for support design. Crack propagation has a huge impact on the durability and reliability of the support. In blasting engineering, the rock mass not only contains a large number of primary fractures but also artificially created fractures, such as preblasting, to form precracks. The presence of precracks not only deteriorates the mechanical properties of the rock mass but also changes the blast stress wave propagation path, which has a significant impact on the blasting effect. Hence, investigation about the mode of crack emergence and the mechanism of damage of cracks in rocks have practical benefits, and it is helpful to understand the fluid flow and transport dynamics in unconventional. Researchers have carried out different studies from experimental, theoretical, and simulation calculations. 
Many researchers have conducted fracture damage studies with rock-like materials. Seven basic crack types (Figure 1) and crack aggregation categories were summarized (Figure 2) [1-3]. Open fissures and closed fissures differed significantly in their mechanical behavior $[3,4]$. Different monitoring tools are applied to monitor the evolution of the fissure development and damage level of microcrack zones. Through the biaxial compression test, Bobet and Einstein [5] obtained the condition that determined crack coalescence category. Hoek's study [6] shows that crack propagation due to a single crack is not convincing enough to explain the macroscopic fracture of the specimen.

In addition, preexisting fractures have strong influence on deformation, maximum strength, and fracture patterns than the effect of confining pressure (5-20 MPa) [7]. The Brazilian splitting test of specimens with prefabricated flaws has also been used to research the failure process of rock [8-13]. Besides, three failure mechanisms are identified and analyzed following shear tests on granite with discontinuous joint [14]. Additionally, the effect of impurities on rock mechanical properties is relatively evident, and the propagation level of shear cracks at the boundary of the impurities is remarkably increased in the specimens containing two impurities [15]. In the studies as mentioned above, the flaws presented in the rock are assumed to be linear or porous defects. Nevertheless, some researchers have concluded that oval flaws are also typical in underground engineering and have carried out fracture damage studies on rock specimens with prefabricated oval fractures [16]. Moreover, an experimental study on single elliptical defect demonstrated that the propagation of tensile cracks around the pore in marble specimens was mainly affected by nucleation and propagation in the local strain zone [17]. However, the available experimental approaches are still insufficient for exploring the associated micromechanisms due to dynamic surveillance in real time has a very high hardware and software requirements about the size of the sensor, accuracy of the signal processing algorithm, and CT scanning while loading is too costly. It is believed that with the improvement of the equipment and the progress of the monitoring technology, it will give a strong impetus to the study.

Crack extension in brittle rock materials has long been investigated by means of theoretical derivations. They can be roughly divided into three categories, elaborated in terms of stress $[5,18-22]$ and starting from energy theory [23-28] and analyzed from the strain point of view $[29,30]$. Yet, the abovementioned criteria are based on the failure of the rock under tensile loading instead of compressive loading. These criteria are available when crack opening occurs, but they are unable to foresee the fracture behavior in closed fissure. The failure criterion is often established with laboratory experiments or ideal hypothetical conditions, and although it reflects the rock failure to a large extent, in actual engineering, the theoretical model cannot fully reflect the damage process of the rock due to the real force situation.

As an important research method, numerous numerical simulation studies on rock fracture process have been carried out, which supplement and verify laboratory experiments and are particularly useful for the cases that cannot be done in the laboratory. The numerical methods mainly include the finite element method, boundary element method, and discrete element method. As the most widely used and versatile modelling the crack propagation and coalescence method, PFC2D is the most representative discrete element method. A bonded-particle model (BPM) is used to build a variety of prefabricated fracture models to simulate the development of fractures during damage in a variety of rocks, and the results of the study validate the laboratory results [31-34]. Sensitivity analysis for the microparameters of the BPM model to the macromechanical parameters of rocks have been carried; a calibration method was proposed for determining the microparameters of the BPM model [35]. Three problems inherent in using BPM to the study of rock mechanics and their reasons have been well explained [36]. Moreover, researches modelled using the finite element method and nonlinear dynamic method demonstrated that the composite crack types and the order of crack initiation as well as the patterns of fracture have a difference with rocks under various loading conditions [37]. In addition, a comparative study of experimental and numerical simulations of splitting tests in Brazil has demonstrated the efficiency and simplicity of the boundary element method compared to PFC2D [10].

As mentioned above, in experiments using various rocklike materials to study crack propagation, the particle consolidation of the materials used may result in much lower compression/tension strength (UCS/T $T_{s}$ ) than those in real rocks. When studying the fracture damage process in rocks using PFC's BPM model, the failure of particle interlock cannot be depicted, which is again responsible for the lower $\mathrm{UCS} / T_{s}$ compared to natural rock. Correspondingly, the BPM is not applicable to evaluate the effect of $\mathrm{UCS} / T_{s}$. In addition, most of the previous research has been carried out on single or a number of parallel prefabricated flaw models, or two straight joint models with a variable distribution, whereas in geotechnical engineering, flaws in natural rock often exist in a crossed form. Hence, an experimental study of crack expansion has been carried out and analyzed in depth using numerical simulations. Uniaxial compression tests are firstly conducted on samples to study the fracture process of flawed rock. With the help of flat-joint model (FJM) of PFC2D, the crack extension of prefabricated flaw rock specimens is simulated and the effect of different $\mathrm{UCS} / \mathrm{T}_{s}$ on crack types and failure mechanisms was investigated by varying the microscopic parameters. The results of the study provide implications for the crack expansion and coalescence pattern of cross fissures.

\section{Experimental Samples and Equipment}

The rock specimens used for the experiments were sandy mudstone with a size of $70 \mathrm{~mm} \times 35 \mathrm{~mm} \times 140 \mathrm{~mm}$. A circular hole of $1 \mathrm{~mm}$ diameter was then drilled in each specimen, and flaws were prefabricated by wire cutting. The pair of cross-flaws is each made up of a $12 \mathrm{~mm}$ long primary flaw crossed by a $8 \mathrm{~mm}$ long minor flaw. The main and minor flaws intersect at a certain angle. $\alpha$ oil and gas 


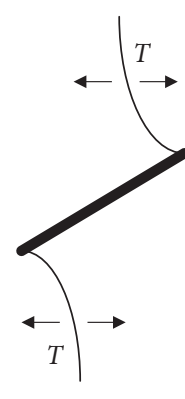

(a)

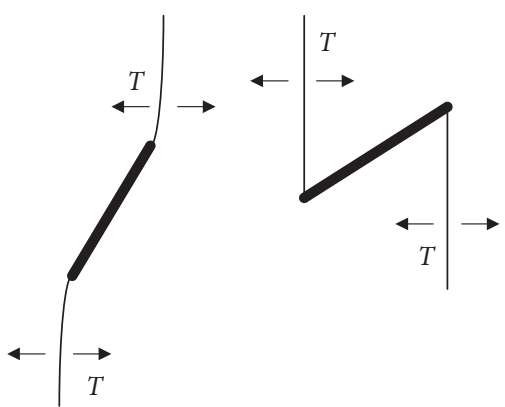

(b)

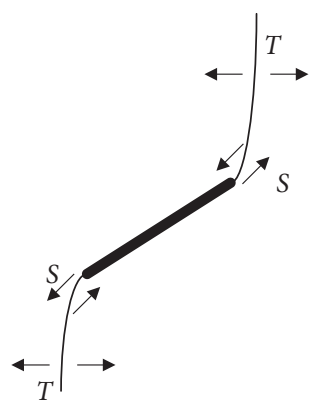

(d)

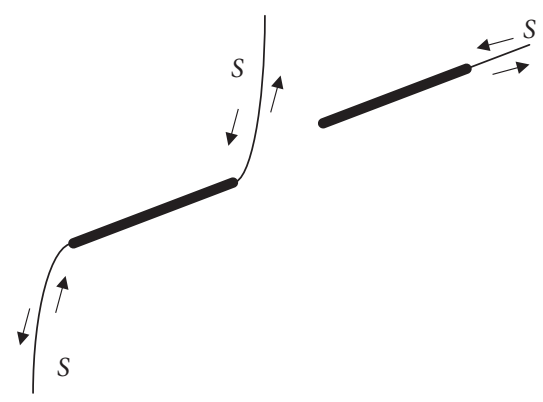

(e) (f)

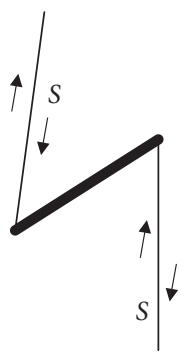

(g)

Figure 1: Types of cracks (T-tensile cracks; S-shear cracks). (a) Type 1 tensile crack (tensile wing crack). (b) Type 2 tensile crack. (c) Type 3 tensile crack. (d) Mixed tensile-shear crack. (e) Type 1 shear crack. (f) Type 2 shear crack. (g) Type 3 shear crack.

extraction indicates (Figure 3 ) the angle of primary flaw and the load $(F), \alpha=0^{\circ}, 15^{\circ}, 30^{\circ}, 45^{\circ}, 60^{\circ}, 75^{\circ}, 90^{\circ} ; L_{r}$ is the distance formed by the two primary flaws, i.e., $L_{r}=6,12,18,24 \mathrm{~mm}, \quad$ respectively. $\quad a=6 \mathrm{~mm}$; $L_{r}=a, 2 a, 3 a, 4 a$. Variations in the geometric parameters of the two flaws result in nine prefabricated cross-flaw specimen models (Table 1). Three rock specimens are produced for each model, for a total of 27 rock specimens prepared, and each model can be named in the following way: $2 a-0$ indicates that $L_{r}=2 a=12 \mathrm{~mm}, \alpha=0^{\circ}$.

Laboratory experiments were carried out on standard cylindrical specimens $(50 \times 100 \mathrm{~mm})$ and the basic physical and mechanical parameters of the rock specimens were obtained (Table 2).

The loading device used for the experiments was the MTS-816 rock mechanics test system. A high-speed camera recording system was used to capture the initiation, propagation, and coalescence of cracks during each test (Figure 4). The loading speed is $0.002 \mathrm{~mm} / \mathrm{s}$. The recording parameters of the high-speed camera are set to record 100 frames per second.

\section{Experimental Results}

3.1. Crack Trajectory. Under the action of the load, the cracks generally behave as three-dimensional cracks, and these cracks often cause the strength of the rock to decrease or even fracture. The crack expansion trajectory is very sensitive to the geometry, stress, size, and location of the crack, especially the three-dimensional crack has a very complex stress-strain field inside the crack.

3.1.1. Effect of $k$. The destabilization and damage process of the fractured rock mass is mainly controlled by the internal locking section rock-bridge and structural surface. Under the influence of external forces, the internal structural surface of the rock mass gradually nucleates, expands, and penetrates the locking section bridge, leading to the destabilization of the whole rock mass. Therefore, the internal locking section bridge penetration of the fractured rock body with end cracking plays a key role in the overall destabilization and damage process of the rock body. Joint persistency $k$ can be defined [14]. In the case of cross-flaws, we defined $k$ as the ratio of the sum of the lengths of the main flaws to that of the lengths of the rock bridge and main flaws, for example, for a specimen with $\alpha=45^{\circ}$, and the two main flaws are in parallel (Figure 5). $k$ is expressed as follows:

$$
k=\frac{2 L_{j}}{L_{r}+L_{j}},
$$

where $L_{r}$ and $k$ are shown in Table 3.

As shown in Figure 6, the crack initiation (first figure), propagation (second figure), and coalescence (third figure) during the tests of three samples with differing joint persistence parameters are recorded by the photographic recording device.

When $k=0.57$, type I tensile cracks initiate first (Figure 6(a)). Hybrid cracks appear at the right end of the key flaw when the axial load increases to a certain degree. As shown in Figure 6, after merging to the secondary cracks, the type I tensile wing cracks expand continuously under loads. Meanwhile, the hybrid cracks are generated at the right end of top main flaw and will converge. However, their coalescence zone is not in the middle of the two groups of defects. Comparing the existing classification of crack aggregation, it is found that this is a new species that can be called category $X$. It is based on the method developed by 


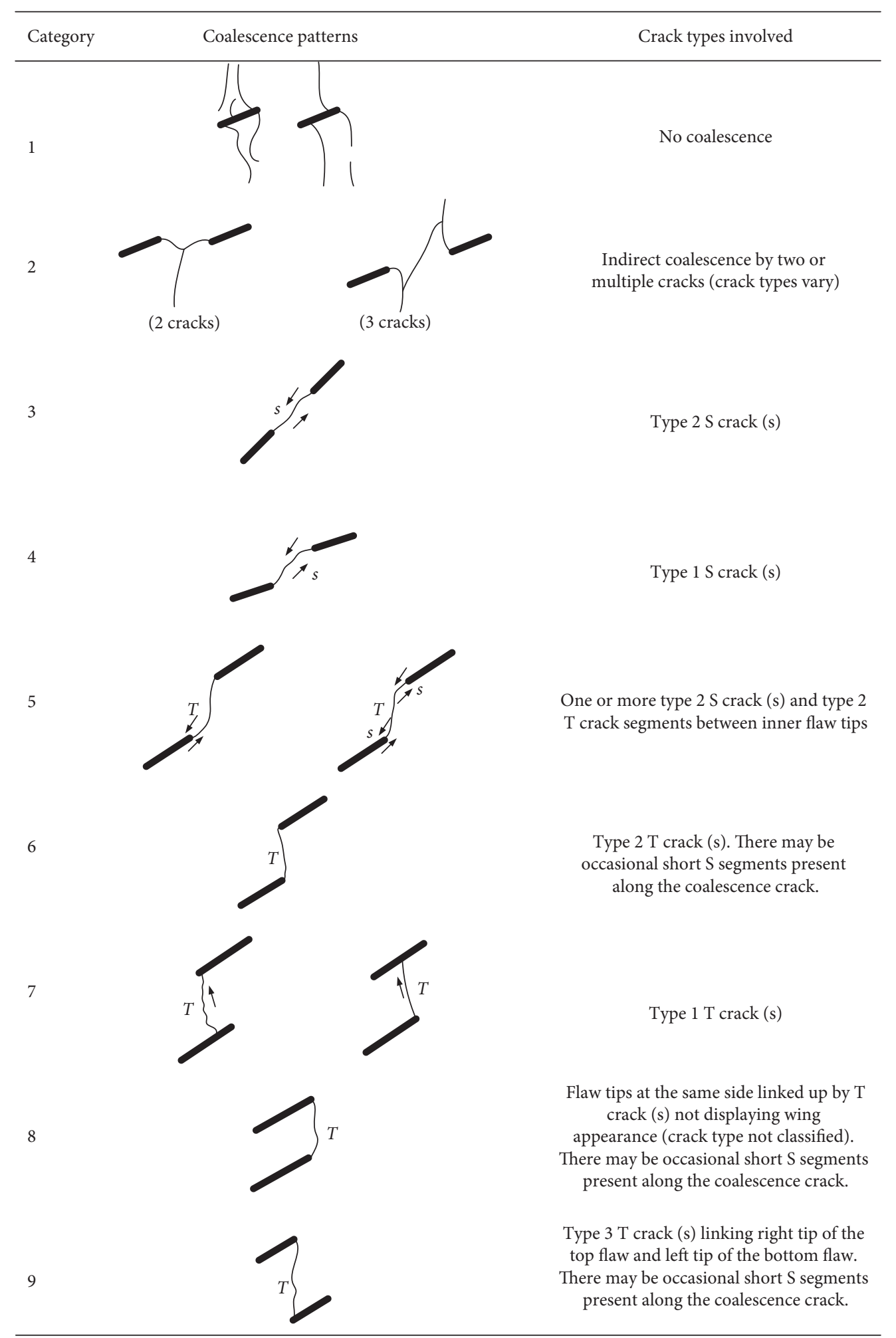

FIGURE 2: Classification of crack coalescence categories (Wong's classification method).

Wong (Figure 2). The final form of damage of this specimen is due to two main cracks in one line and inclined at an angle of $45^{\circ}$ to the axial load. The specimen is subjected to axial forces, and the tensile cracks expand to form a damage surface. This results in the axial load forming a shear force on the oblique damage surface and thus converting into shear damage.

For $k=0.67$, type III tensile cracks initiate first at the right end of the top-right key flaw. After that, the left end of the bottom-left key flaw also initiates this kind of cracks, 


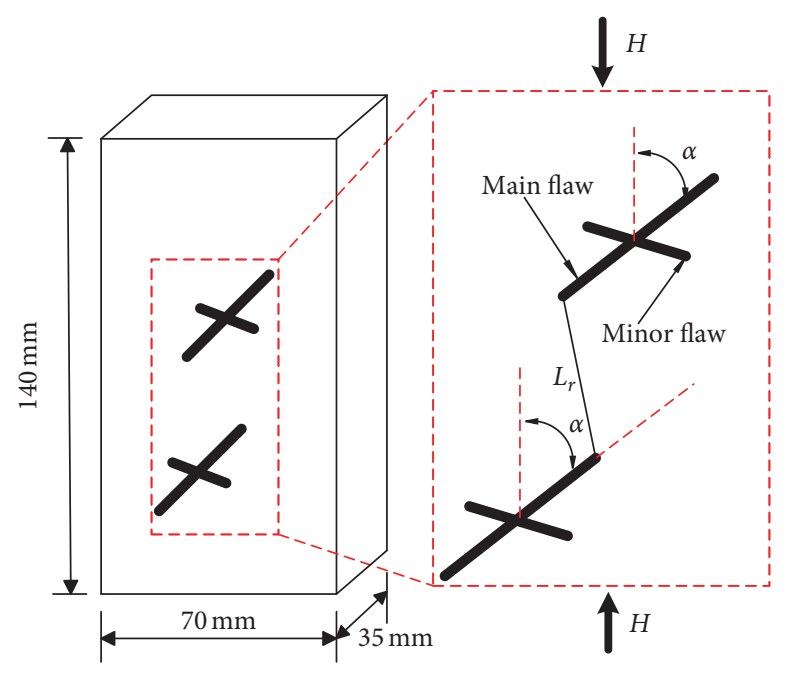

(a)

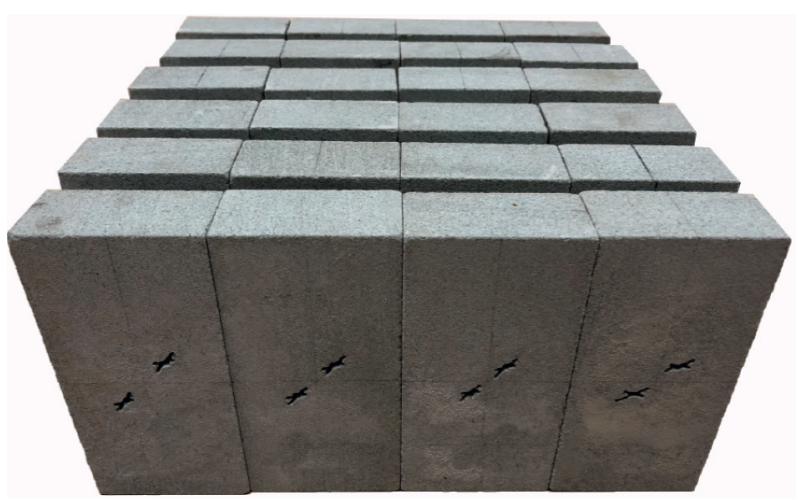

(b)

FIGURE 3: Experimental specimens: (a) models of prefabricated flaws, and (b) rock specimens.

TABLE 1: List of names for models.

\begin{tabular}{lcc}
\hline Specimens number & $L_{r}(\mathrm{~mm})$ & $\alpha\left(^{\circ}\right)$ \\
\hline$a-45$ & $a$ & \\
$2 a-45$ & $2 a$ & 45 \\
$3 a-45$ & $3 a$ & \\
$2 a-15$ & $2 a$ & 15 \\
$2 a-30$ & $2 a$ & 30 \\
$2 a-45$ & $2 a$ & 45 \\
$2 a-60$ & $2 a$ & 60 \\
$2 a-75$ & $2 a$ & 75 \\
$2 a-90$ & $2 a$ & 90 \\
\hline
\end{tabular}

TABle 2: Mechanical parameters of the rocks used in the experiments.

\begin{tabular}{lc}
\hline Properties & Sandy mudstone specimen \\
\hline Density $\left(\mathrm{g} / \mathrm{cm}^{3}\right)$ & 2.30 \\
Young's modulus $(\mathrm{GPa})$ & 4.51 \\
Uniaxial compressive strength $(\mathrm{MPa})$ & 28.12 \\
Tensile strength $(\mathrm{MPa})$ & 1.73 \\
Poisson's ratio & 0.27 \\
\hline
\end{tabular}

which propagate downward (Figure 6(b)). With increasing load, the top-right main flaw and minor flaw are linked through type III tensile cracks. Thereafter, hybrid cracks initiate at the intersection and the left end of the key flaw. Type I tensile cracks are generated near the bottom-left key flaw, while hybrid cracks are initiated at the right end. Eventually, the hybrid tensile-shear cracks are connected within the two key flaws, and then coalescence occurs. The cracks continuously propagate under stress, resulting in oblique shear failure. This crack coalescence belongs to category VII [2].

For $k=0.8$, type III tensile cracks appear at the right end of the key flaw and at both ends of the key flaw in the lower left position (Figure 6(c)). The tensile cracks are linked to the secondary cracks, changing into type II tensile cracks under

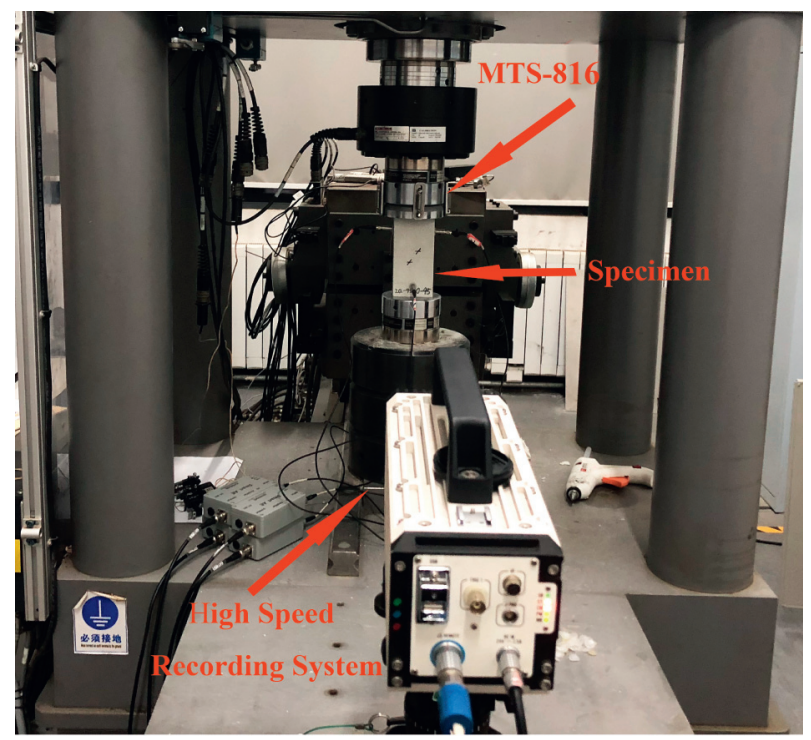

Figure 4: Loading devices and recording devices used for experiments.

stress while the loading is increasing. Simultaneously, the secondary crack (shear crack) starts at the intersection of the tensile crack and the primary flaw in the upper right. These shear cracks connect and coalesce with the tensile cracks from the bottom-left main flaw, ultimately forming crack coalescence in category II.

As shown in Figure 6, for the same $\alpha$, different joint persistency affects crack propagation and coalescence, leading to differences in the final failure mode of the rocks.

3.1.2. Effect of $\alpha$. To examine the effect of the angle $\alpha$ on crack propagation and coalescence, $L_{r}=2 a, k=0.67$. The photographs of six specimens are shown in Figure 7.

In the specimen $2 a-15$ (Figure $7(\mathrm{a})$ ), type III tensile cracks occur at the bottom minor flaw, then they grow 


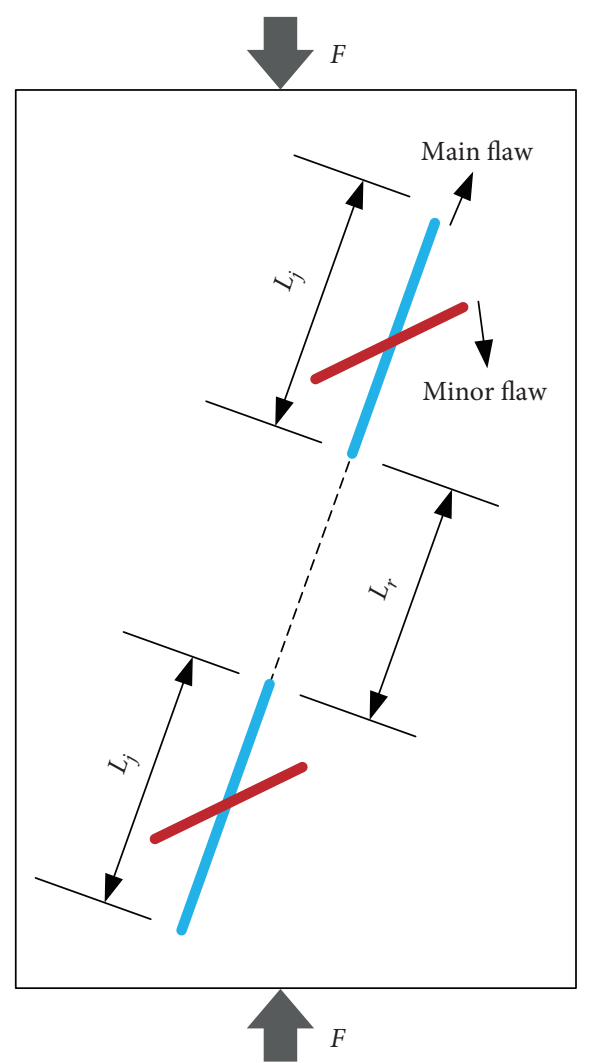

FIGURE 5: A schematic diagram of joint persistency.

TABle 3: List of $k$.

\begin{tabular}{lcc}
\hline Specimens number & $L_{r}(\mathrm{~mm})$ & $k$ \\
\hline$a-45$ & 6 & 0.8 \\
$2 a-45$ & 12 & 0.67 \\
$3 a-45$ & 18 & 0.57 \\
\hline
\end{tabular}

downward. Subsequently, these cracks propagate upward. With the loads increasing, tensile cracks appear at the ends of the top subordinate flaw. Crack coalescence is achieved through the tensile cracks. It is classified as category IV. In the sample $2 a-30$, the primary and minor flaws are first linked through the initiated type III tensile cracks (Figure 7(b)). Type I tensile cracks appeared first from the top primary flaw. Subsequently, tensile cracks appeared at the left end of subordinate flaw, whereas the secondary cracks started at its right end. Also, a secondary crack sprouted at the lower end of the primary at the top. These cracks are connected between the upper and lower crossflaws within the rock bridge; this polymerization pattern can be classified to category IX.

Based on the above analysis method, the same analysis is performed for Figures 7(c), 7(d), 7(e), and 7(f). Using the classification method of crack coalescence according to Figure 2, the following results can be obtained. The crack coalescence of the specimen $2 a-45$ (Figure $7(\mathrm{c})$ ), the specimen 2a-60 (Figure 7(d)), the specimen 2a-75 (Figure 7(e)), and the specimen 2a-90 (Figure $7(\mathrm{f})$ ) can be classified to category II, VIII, I, and II, respectively.
According to Figure 7, mixed tensile-shear cracks do not occur for $\alpha<45^{\circ}$, and they start to emerge for $\alpha<45^{\circ}$. When $\alpha<30^{\circ}$, the cracks are first initiated at the tip of the minor flaw; when $\alpha \geq 30^{\circ}$, the cracks are first generated at the tip of the main flaw. The change of the angle $\alpha$ affects the crack type and first initiation position for cross-flaws. When $\alpha \leq 45^{\circ}$, the crack expansion mode is mainly along the joint surface and the direction of crack extension, and the shape of rack is wing type. Among which, $\alpha=0^{\circ}$ is mainly along the joint surface extension crack, $\alpha=15^{\circ}$ starts to appear like wing type crack, $\alpha=30^{\circ}, 45^{\circ}$, the rock has obvious damage angle and complete damage surface, and $\alpha=45^{\circ}$ wing type and antiwing type crack exist at the same time. When $\alpha>45^{\circ}$, the crack extension mode is along the joint surface, generating anti-wing type cracks. When, $\alpha=60^{\circ}$, there are obvious anti-wing type cracks extending along the joint surface and forming X-shaped fractures with a large number of small fragmentation cracks. When $\alpha=75^{\circ}$ and $90^{\circ}$, cracks are mainly generated along the nodal plane and the vertical nodal plane.

3.2. Stress Analysis. Crack initiation stress and damage stress are not only important characteristic values of rock strength but also the dividing point of different stages of crack expansion. The crack initiation stress characterizes the compression of existing cracks in the rock and the beginning of new cracks, which are in a stable state, while the damage stress characterizes the rapid convergence and unstable expansion of the microcracks that were initiated and expanded in the previous stage, which eventually reach the peak stress of the rock. Therefore, the study of crack initiation stress is important for understanding the progressive damage process of rocks.

3.2.1. Effect of $k$ to Stress. Figure 8 was obtained by the testing. Points $A, B$, and $C$ indicate the first stress drop of rock specimens with $k=0.57,0.67$, and 0.8 , respectively, indicating the crack initiation stresses. Points $D, E$, and $F$ denote the second stress landing, i.e., the crack coalescence stress. To capture the impact of joint persistence on fracture, the ratio $\sigma_{\mathrm{ci}} / \sigma_{c}$ [38-41] was used to represent the crack initiation stress level with respect to the peak stress. The ratio of crack coalescence stress to peak stress can be represented by the $\sigma_{c c} / \sigma_{c} . \sigma_{\mathrm{ci}}$ was defined as the stress at the time of crack initiation while $\sigma_{\mathrm{cc}}$ is the stress at the time of crack coalescence and $\sigma_{c}$ is the peak stress. With the different joint persistency, the $\sigma_{\mathrm{ci}} / \sigma_{c}$ and $\sigma_{\mathrm{cc}} / \sigma_{c}$ ratio values are shown in Table 4 . The curves of $k$ versus $\sigma_{\mathrm{ci}} / \sigma_{c}$ and $\sigma_{\mathrm{cc}} / \sigma_{c}$ are shown in Figure 9.

With increasing $k$ value, the $\sigma_{\mathrm{ci}} / \sigma_{c}$ ratio decreases linearly while the $\sigma_{\mathrm{cc}} / \sigma_{c}$ ratio increases linearly. In other words, the shorter the rock bridge (formed by the primary flaws) in the two groups of cross-flaws, the greater the distance of crack initiation force to peak stress. This means the better the joint persistency of the rocks, the earlier the rock cracks are initiated. The persistence of the joints has a significant effect on the crack initiation stress. It can be concluded that the more fragmented the rock mass is, the 


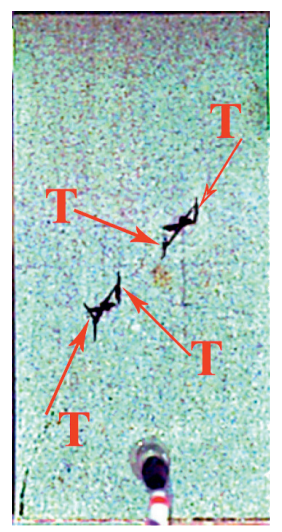

First crack initiation

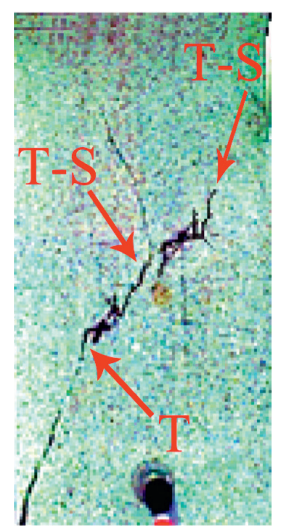

Crack propagation

(a)

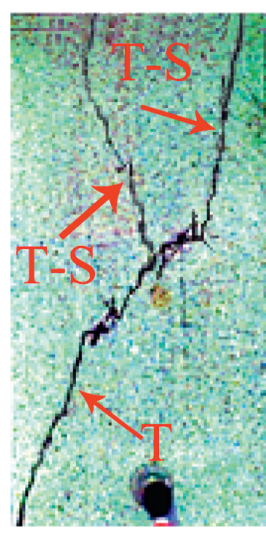

Coalescence

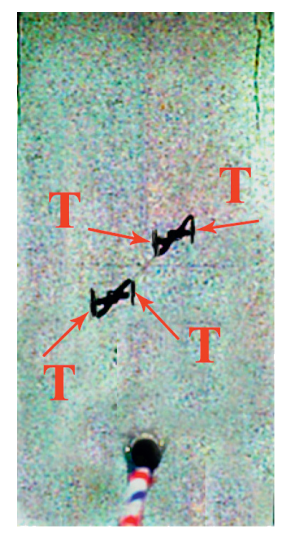

First crack initiation

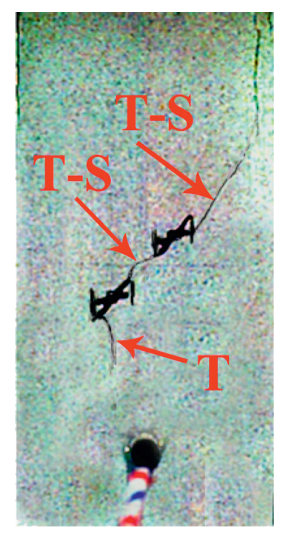

Crack propagation

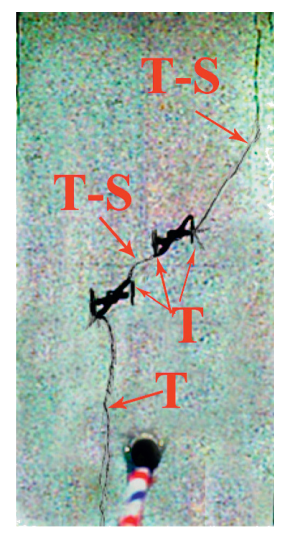

Coalescence

(b)

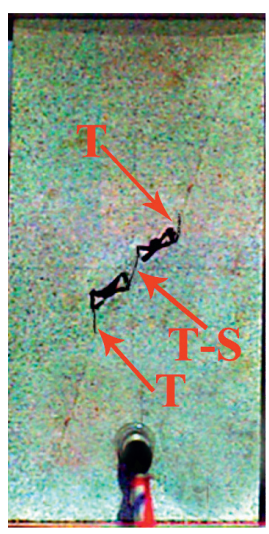

First crack initiation

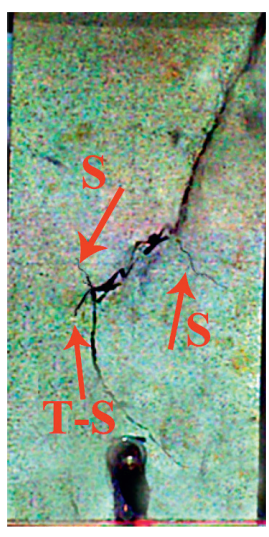

Crack propagation

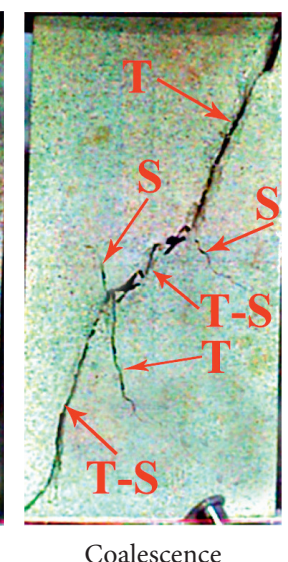

Coalescence

(c)

Figure 6: Crack evolution diagram for three joint continuity parameters: (a) $k=0.57$, (b) $k=0.67$, and (c) $k=0.80$.

more likely it is to be further fragmented into smaller sized rock masses by the loading action. Meanwhile, the crack coalescence stress becomes closer to the peak stress, and the crack coalescence becomes more difficult than the low joint persistency.

3.2.2. Effect of $\alpha$ to Stress. Using the method mentioned in Subsection 3.2.1, the stress-strain curves for $\alpha=15^{\circ}, 30^{\circ}, 45^{\circ}$, $60^{\circ}, 75^{\circ}$, and $90^{\circ}$ are analyzed (Figure 10). $A-F$ represent crack initiation stresses of the samples with $\alpha=15^{\circ}, 30^{\circ}, 45^{\circ}, 60^{\circ}, 75^{\circ}$, and $90^{\circ}$, respectively; $H-M$ indicate the crack polymerization stresses. Table 5 is the $\sigma_{\mathrm{ci}} / \sigma_{c}$ and $\sigma_{\mathrm{cc}} / \sigma_{c}$ ratios with different $\alpha$. The $\sigma_{\mathrm{ci}} / \sigma_{c}$ ratio generally varies between 0.30 and 0.50 , whereas the $\sigma_{c c} / \sigma_{c}$ ratio ranges from 0.7 to 0.90 . These values are consistent with the results of previous studies $[42,43]$. The curves of $\alpha$ versus $\sigma_{\mathrm{ci}} / \sigma_{c}$ and $\sigma_{\mathrm{cc}} / \sigma_{c}$ are shown in Figure 11 .

With increasing angle $\alpha$, both the $\sigma_{\mathrm{ci}} / \sigma_{c}$ and $\sigma_{\mathrm{cc}} / \sigma_{c}$ ratios increase linearly. Their minimum are observed for $\alpha=15^{\circ}$, which means crack initiation and coalescence are the easiest to occur. Their maxima are observed for $\alpha=90^{\circ}$, which means crack initiation and coalescence are the most difficult to occur. Meanwhile, the main flaw is horizontal for $\alpha=90^{\circ}$, which is in agreement with a previous study [33] that a horizontal flaw perpendicular to axial load has shielding effects on the transfer of axial stress and the propagation and coalescence of cracks.

\section{Application of the Flat-Joint Model in Numerical Simulation}

4.1. Model Establishment. The particle flow program (PFC) is a discrete element method, which can solve the problem of discontinuous medium mechanics and analyze the damage mechanism of rocks from a fine view point. PFC uses particle aggregates to simulate rocks and reproduces the mechanical properties of rocks by defining an adhesive contact model between particles to make the particles interact. Based on the size of the experimental samples, it is modelled with a size of $35 \mathrm{~mm} \times 70 \mathrm{~mm} \times 140 \mathrm{~mm}$ sample (Figure 12). The particle radius distribution was $R_{\min }=0.21 \mathrm{~mm}, R_{\min }=0.35 \mathrm{~mm}$. The microscopic parameters required for the model as well as the concepts can be found in Table 6 .

4.2. Calibration of Microparameters. A required job when using discrete element methods for numerical simulations is to determine the microscopic parameters by parameter calibration. The accurate determination of the microscopic parameters is very important for the PFC to correctly 


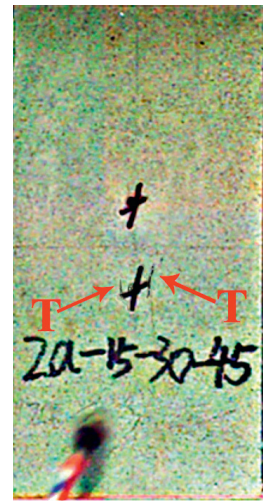

First crack initiation

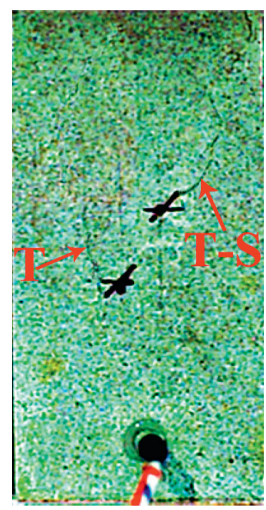

First crack initiation

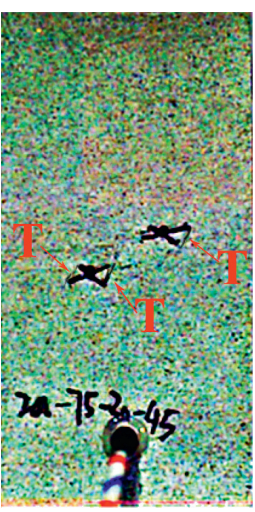

First crack initiation

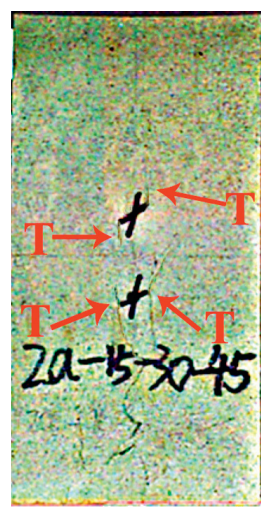

Crack propagation

(a)

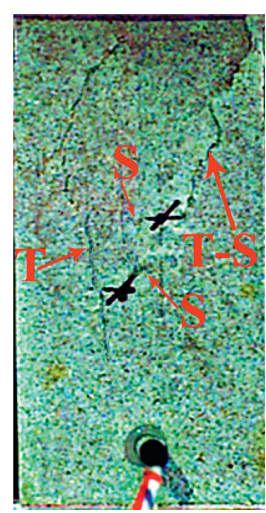

Crack propagation

(c)

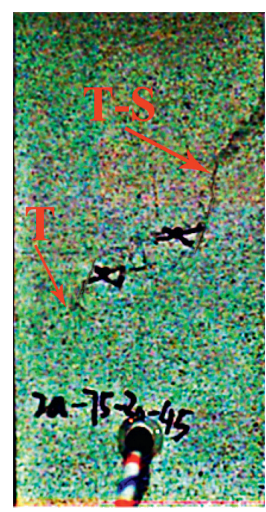

Crack propagation

(e)

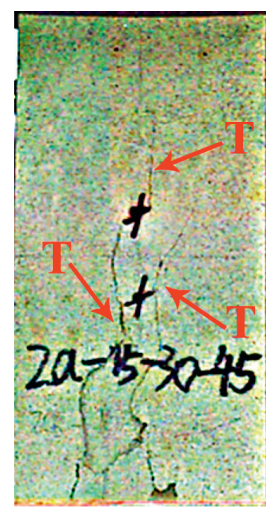

Coalescence

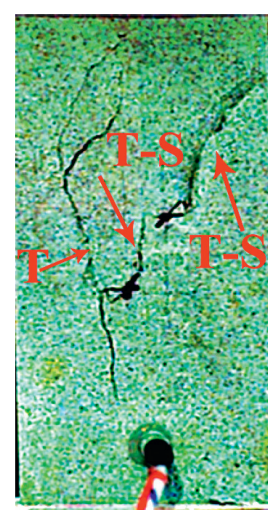

Coalescence

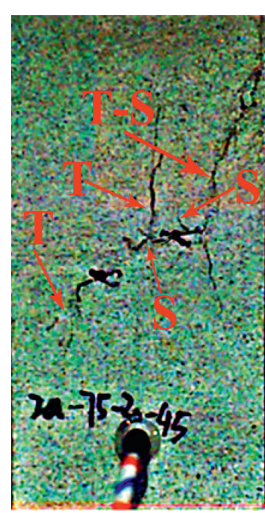

Coalescence

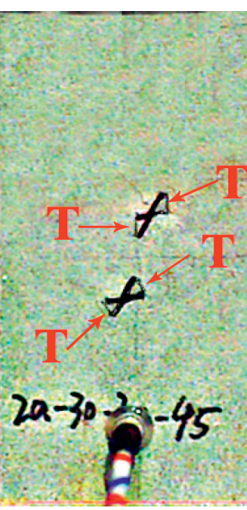

First crack initiation

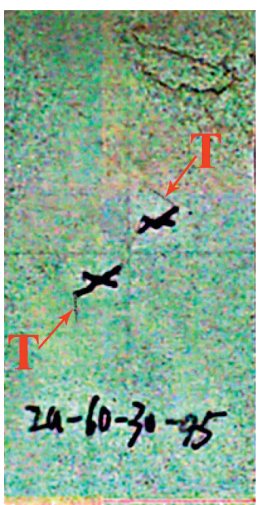

First crack initiation

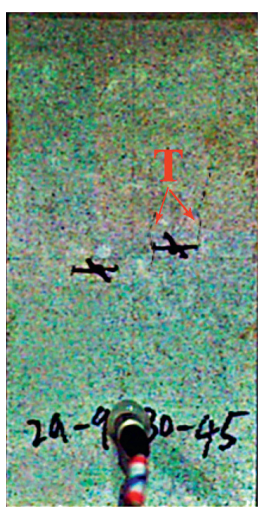

First crack initiation

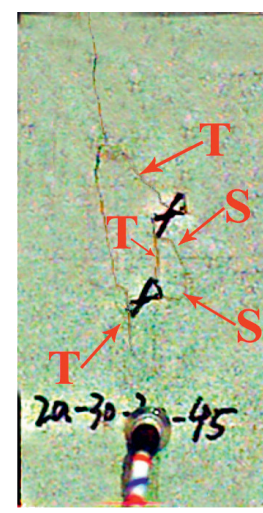

Crack propagation

(b)

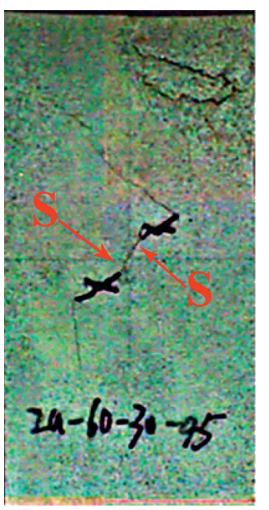

Crack propagation

(d)

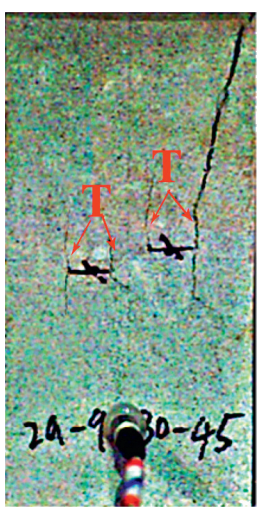

Crack propagation

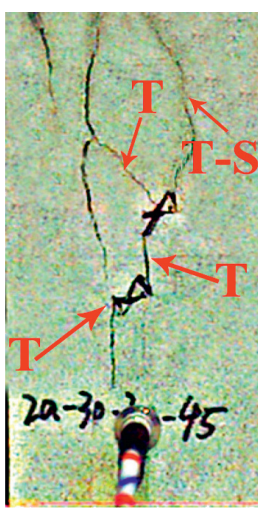

Coalescence

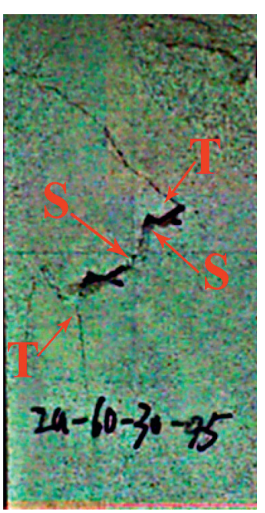

Coalescence

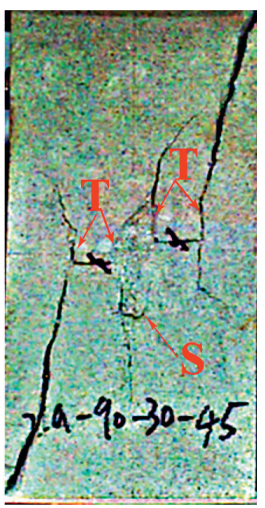

Coalescence

(f)

Figure 7: Crack evolution diagram of $\alpha$ : (a) $\alpha=15^{\circ}$, (b) $\alpha=30^{\circ}$, (c) $\alpha=45^{\circ}$, (d) $\alpha=60^{\circ}$, (e) $\alpha=75^{\circ}$, and (f) $\alpha=90^{\circ}$.

simulate the mechanical properties of the rock. The most commonly used method is the trial-and-error method. That is, the microscopic parameters are continuously adjusted so that the numerical results match the macroscopic mechanical properties of the rock, which is the calibration method used in this study. Table 7 shows the differences between the mechanical parameters obtained after calibration and those obtained experimentally, indicating that the parameters obtained after calibration are reliable.

As shown in Figure 13, A1-A5 are the experimentally obtained stress-strain curves for the five specimens, and the red line is the stress-strain curve obtained from the numerical simulations. Clearly, the FJM model can capture the mechanical behavior, except for the initial compaction stage. 


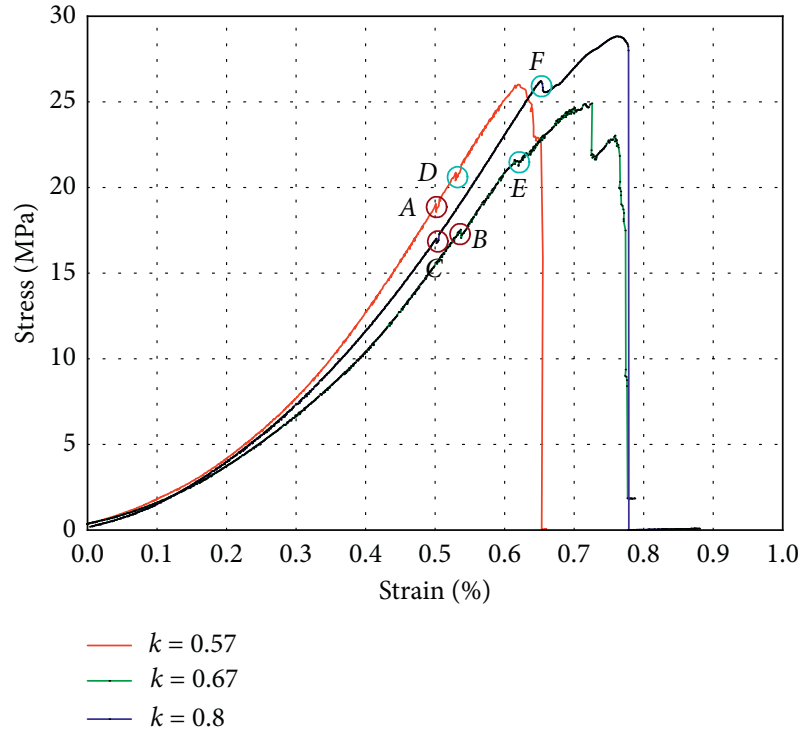

FIGURE 8: Stress-strain curves with different $k$.

TABLE 4: Crack initiation and coalescence forces $\sigma_{\mathrm{ci}} / \sigma_{c}$ and $\sigma_{\mathrm{cc}} / \sigma_{c}$ for different joint persistency.

\begin{tabular}{lccccc}
\hline$k$ & $\sigma_{\mathrm{ci}}(\mathrm{MPa})$ & $\sigma_{\mathrm{ci}}(\mathrm{MPa})$ & $\sigma_{c}(\mathrm{MPa})$ & $\sigma_{\mathrm{ci}} / \sigma_{c}$ & $\sigma_{\mathrm{cc}} / \sigma_{c}$ \\
\hline 0.57 & 18.95 & 20.79 & 26.32 & 0.76 & 0.79 \\
0.67 & 16.85 & 21.32 & 24.91 & 0.68 & 0.86 \\
0.8 & 17.07 & 26.20 & 28.93 & 0.59 & 0.91 \\
\hline
\end{tabular}

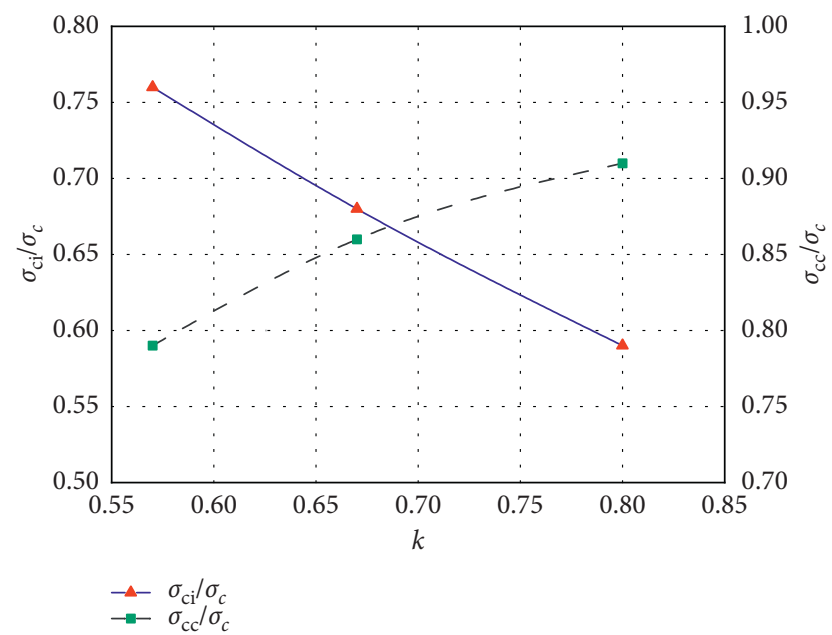

FIGURE 9: Joint persistency $k$ versus crack initiation and coalescence forces $\sigma_{\mathrm{ci}} / \sigma_{c}$ and $\sigma_{\mathrm{cc}} / \sigma_{c}$.

\subsection{Results Obtained from FJM Model}

4.3.1. Results about Different $k$. The FJM model for $k=0.57$, 0.67 , and 0.80 and the associated screenshots of crack evolution and the final fracture pattern in the experiment are presented in Figure 14 (red color indicates the shear cracks

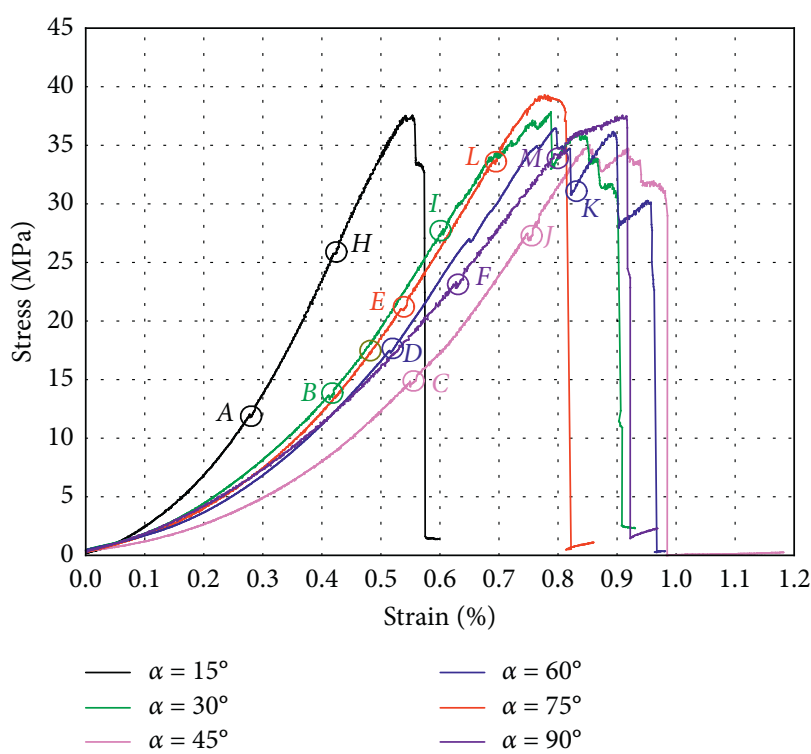

Figure 10: Stress-strain curves with different $\alpha$.

TABLE 5: $\sigma_{\mathrm{ci}} / \sigma_{c}$ and $\sigma_{\mathrm{cc}} / \sigma_{c}$ for different angles between the main flaw and axial load $F$.

\begin{tabular}{cccccc}
\hline$\alpha^{(\circ)}$ & $\sigma_{\mathrm{ci}}(\mathrm{MPa})$ & $\sigma_{\mathrm{cc}}(\mathrm{MPa})$ & $\sigma_{c}(\mathrm{MPa})$ & $\sigma_{\mathrm{ci}} / \sigma_{c}$ & $\sigma_{\mathrm{cc}} / \sigma_{c}$ \\
\hline 15 & 12.06 & 26.00 & 37.68 & 0.32 & 0.69 \\
30 & 13.68 & 27.73 & 37.99 & 0.36 & 0.73 \\
45 & 14.70 & 27.66 & 35.01 & 0.42 & 0.79 \\
60 & 17.51 & 30.68 & 36.53 & 0.48 & 0.84 \\
75 & 21.29 & 33.90 & 39.42 & 0.54 & 0.86 \\
90 & 23.36 & 34.29 & 37.68 & 0.62 & 0.91 \\
\hline
\end{tabular}

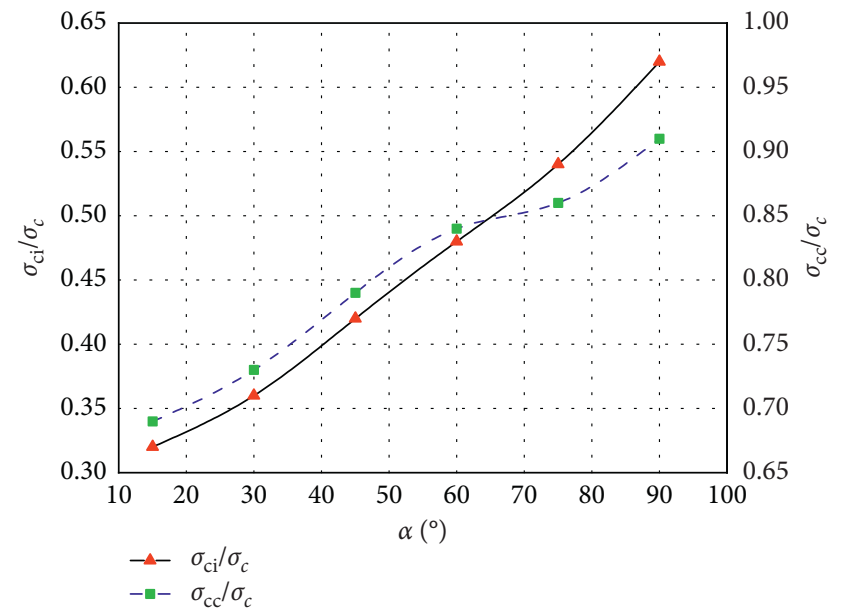

FIgURE 11: The angle between the main flaw and axial load $\alpha$ versus crack initiation and coalescence forces $\sigma_{\mathrm{ci}} / \sigma_{c}$ and $\sigma_{\mathrm{cc}} / \sigma_{c}$.

and white color indicates the tensile cracks, respectively). The first cracks are white wing tensile cracks, which are generated after the axial stress reaches 16.04 MPa. Such cracks initially occur at the tips of the two main flaws and propagate along the axial direction under load (Figure 14(a)). Meanwhile, red shear cracks are generated. 


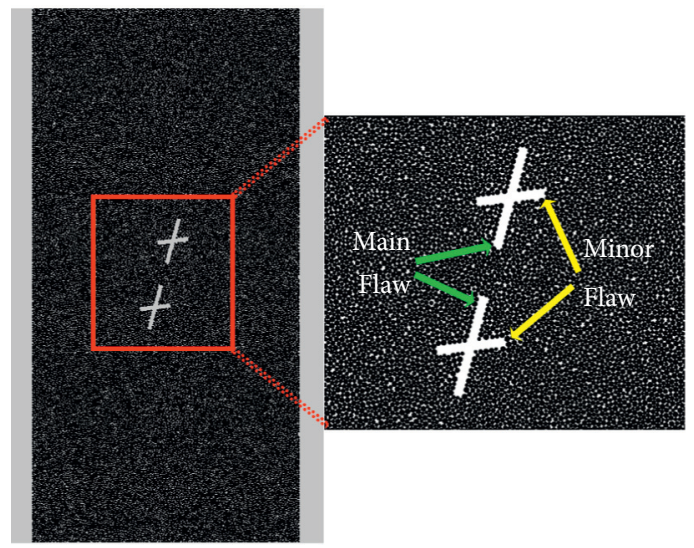

FIGURE 12: Model established by FJM corresponding to the experiment.

TABLe 6: Microparameters of the FJM.

\begin{tabular}{lcc}
\hline Microparameter & Physical meaning & Assigned value \\
\hline$R_{\min }(\mathrm{mm})$ & Minimum radius of particles & 0.21 \\
$R_{\max } / R_{\min }$ & Ratio of maximum radius to minimum radius of particles & 1.66 \\
$g_{\text {ratio }}$ & Installation gap ratio & 0.3 \\
$\Phi_{B}$ & The proportion of the bonding particles & 0.9 \\
$\Phi_{S}$ & The proportion of slit particles & 0.1 \\
$N_{r}$ & Number of elements in radial direction & 3 \\
$E_{c}=\bar{E}_{c}(\mathrm{GPa})$ & Effective modulus of both the particle and bond \\
$k_{n} / k_{s}=\bar{k}_{n} / \bar{k}_{s}$ & Normal-to-shear stiffness ratio of both the particle and bond \\
$\sigma_{b}(\mathrm{MPa})$ & Tensile strength \\
$c_{b}(\mathrm{MPa})$ & Cohesion strength \\
$\left.\Phi_{b}{ }^{\circ}\right)$ & Friction angle \\
\hline
\end{tabular}

TABle 7: Difference of calibrated parameters with obtained parameters from experiments.

\begin{tabular}{lccc}
\hline Name of properties & Experiments & Numerical simulations & Difference $(\%)$ \\
\hline Young's modulus $(\mathrm{GPa})$ & 4.51 & 4.47 & -0.89 \\
Uniaxial compressive strength $(\mathrm{MPa})$ & 28.12 & 28.00 & -0.43 \\
Tensile strength $(\mathrm{MPa})$ & 1.73 & 1.79 & 3.35 \\
Poisson's ratio & 0.27 & 0.26 & -3.85 \\
\hline
\end{tabular}

Additionally, wing tensile cracks and shear cracks emerge at the tips of the two minor flaws. Thereafter, the secondary cracks are also initiated at the tips of minor flaws and connect with the tip of the main flaw. The peak stress is 22.43 MPa, and when the stress changes to 21.03 MPa, crack coalescence occurs. The other two specimens for different joint persistency parameter values are subjected to the same analysis.

4.3.2. Results about Different $\alpha$. Figure 15 illustrates the figures of crack initiation, propagation, coalescence processes for $\alpha=30^{\circ}, 60^{\circ}$, and $90^{\circ}$ and fracture in the experiment.

When $\alpha=30^{\circ}$ (Figure 15(a)) and $90^{\circ}$ (Figure 15(c)), crack propagation is first completed around the two groups of cross-flaws and then in the rock bridge region formed by main flaws. However, when $\alpha=60^{\circ}$ (Figure 15(b)), the first and secondary cracks initially coalesce with each other in the rock bridge region formed by main flaws following their generation at the flaw tip; then, coalesce occurs around the cross-flaws. Moreover, for $=30^{\circ}$ and $90^{\circ}$, the first cracks initially occur at the flaw tip, whereas for $\alpha=60^{\circ}$, the first cracks are simultaneously generated at the flaw tip and in its vicinity. When $\alpha=90^{\circ}$, the main flaw is horizontally arranged, which forms an angle of $90^{\circ}$ with axial load. The angle between the minor flaw and axial load is $\alpha<90^{\circ}$, and the first crack initially occurs at the tip of minor flaw.

\section{Discussion}

5.1. Effect of the UCS/TS Ratio on Crack Propagation and Coalescence. The UCS/TS ratio is an important mechanical parameter. It can impact the failure process and is an important characteristic of brittle rock. The ratio of uniaxial compression to uniaxial tensile strength (compressiontension ratio) of rocks is much higher than 1.0. This is an important difference between rock materials and other 


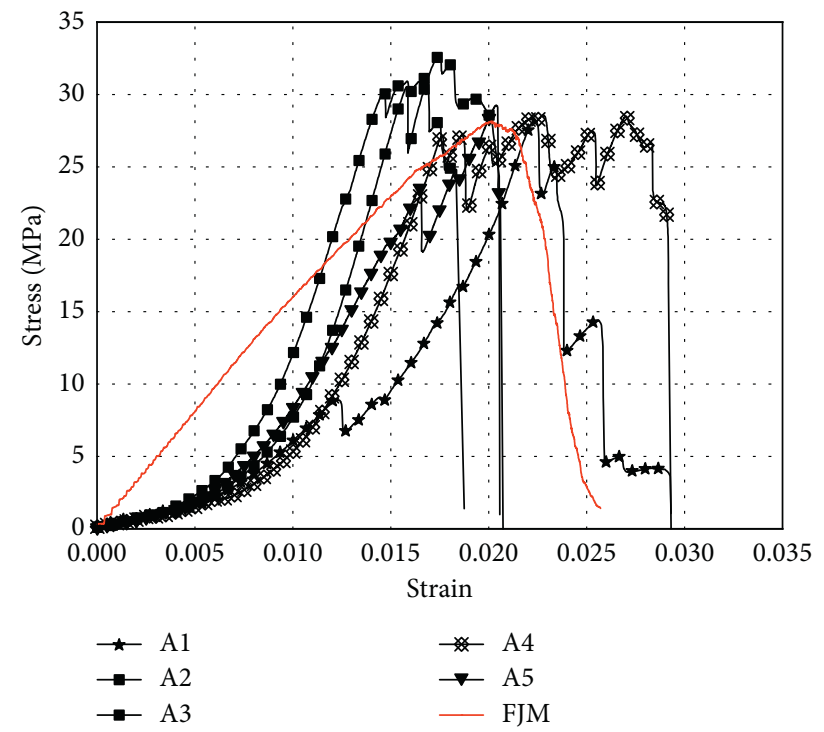

FIgURE 13: Stress-strain curves obtained from experimental and numerical simulations.

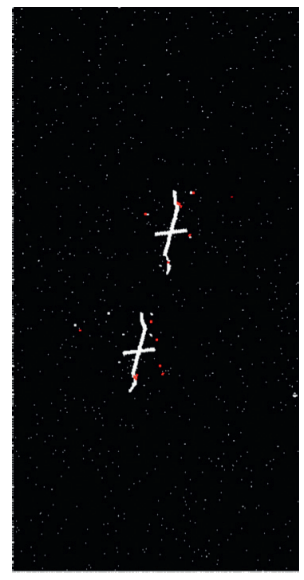

Crack initiation

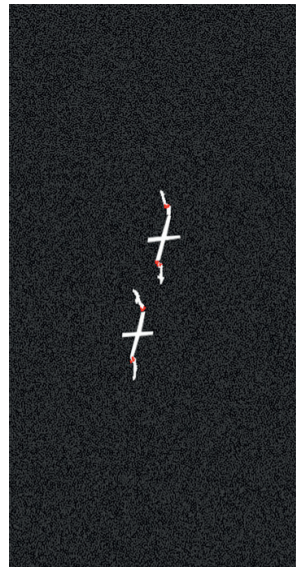

Crack initiation

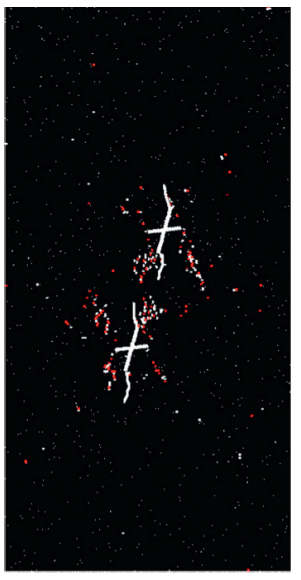

Crack propagation

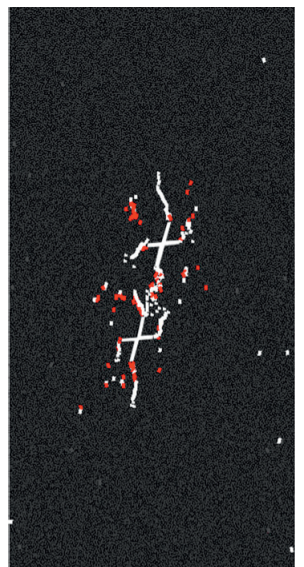

Crack propagation

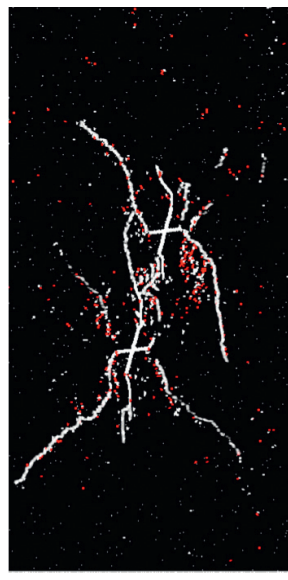

Crack coalescence

(a)

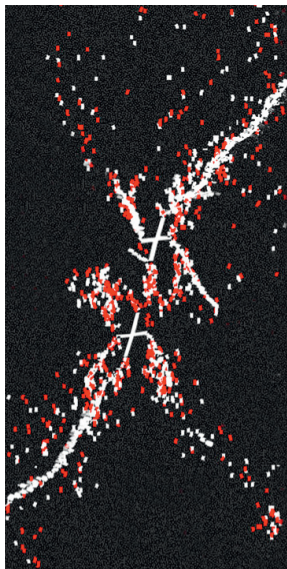

Crack coalescence

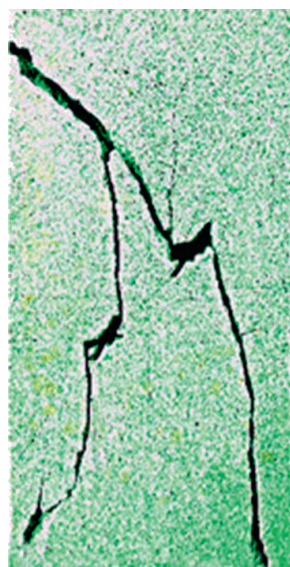

Fracture in experiment

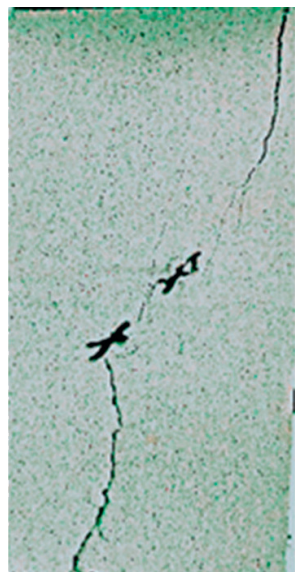

Fracture in experiment

(b)

Figure 14: Continued. 


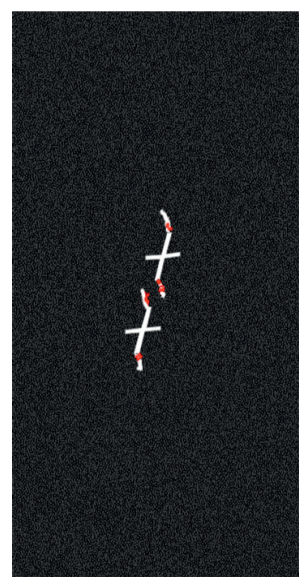

Crack initiation

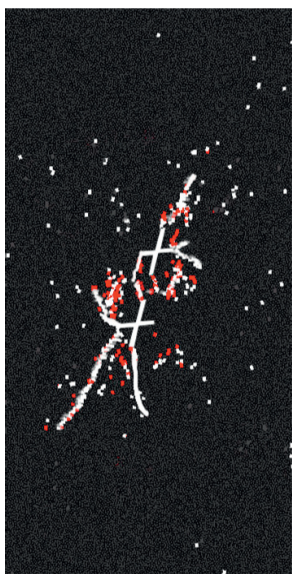

Crack propagation

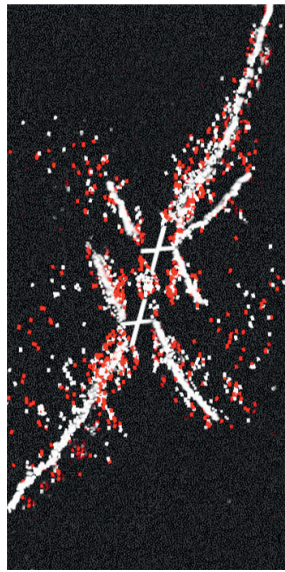

Crack coalescence

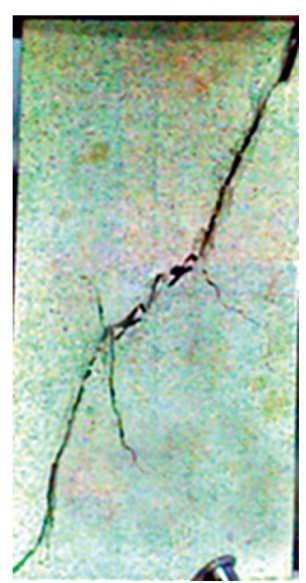

Fracture in experiment

(c)

FIGURE 14: Diagram of crack propagation process shown by simulation results at different $k$ values and the experimentally obtained results: (a) $k=0.57$. (b) $k=0.67$. (c) $k=0.80$.

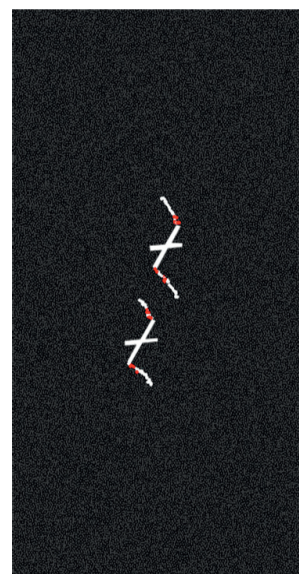

Crack initiation

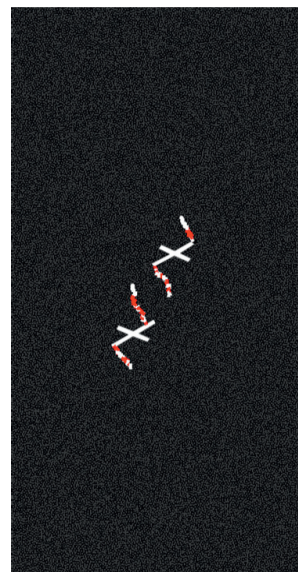

Crack initiation

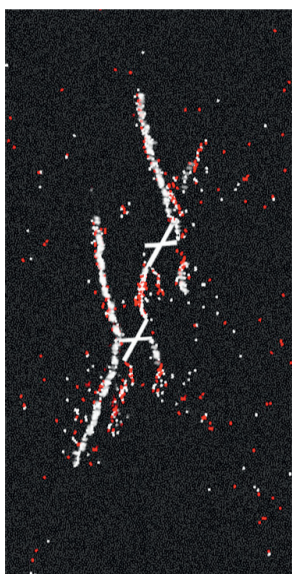

Crack propagation

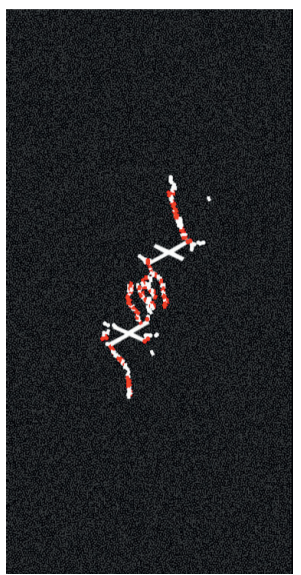

Crack propagation

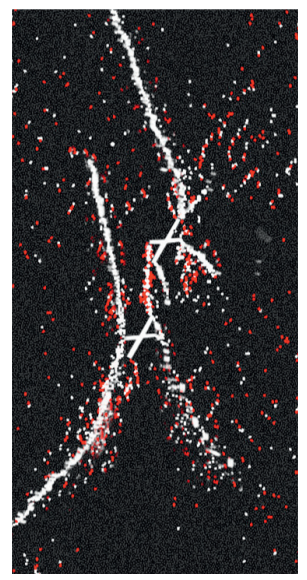

Crack coalescence

(a)

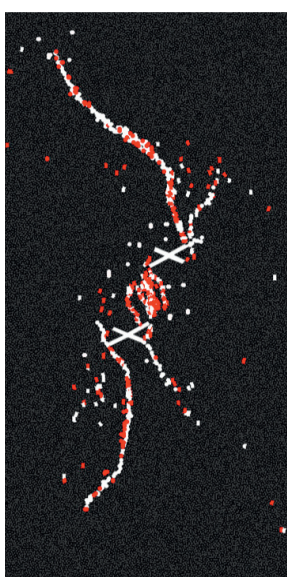

Crack coalescence

(b)

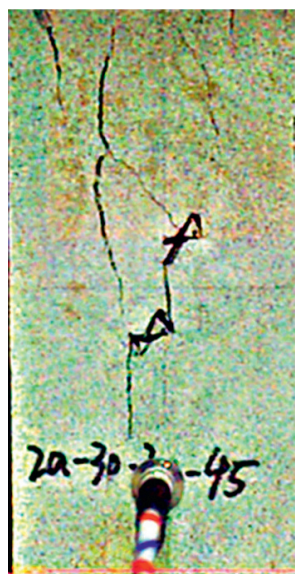

Fracture in experiment

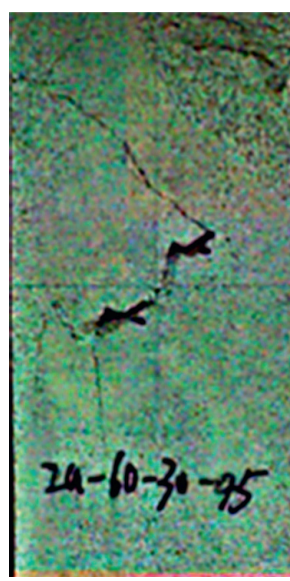

Fracture in experiment

Figure 15: Continued. 


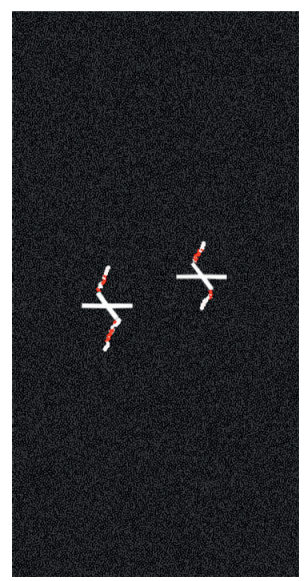

Crack initiation

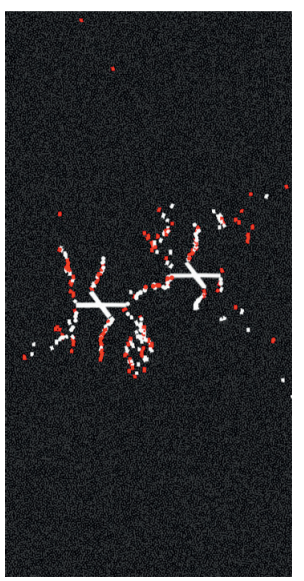

Crack propagation

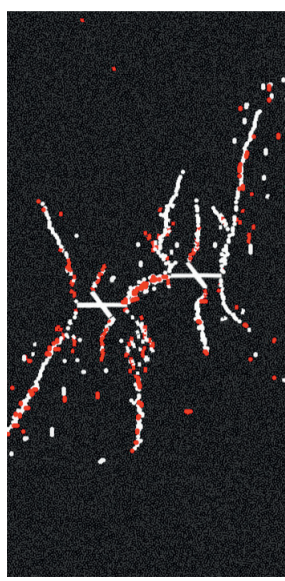

Crack coalescence

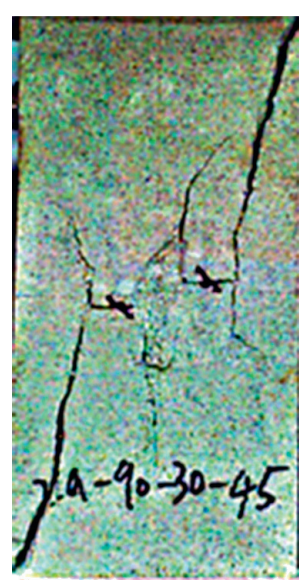

Fracture in experiment

(c)

FIGURE 15: Diagram of crack propagation process shown by simulation results at different $\alpha$ values and the experimentally obtained results: (a) $\alpha=30^{\circ}$, (b) $\alpha=60^{\circ}$, and (c) $\alpha=90^{\circ}$.

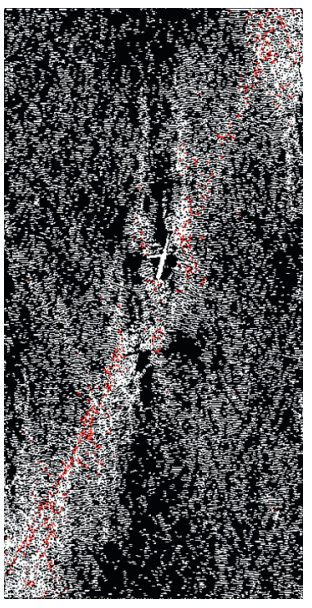

(a)

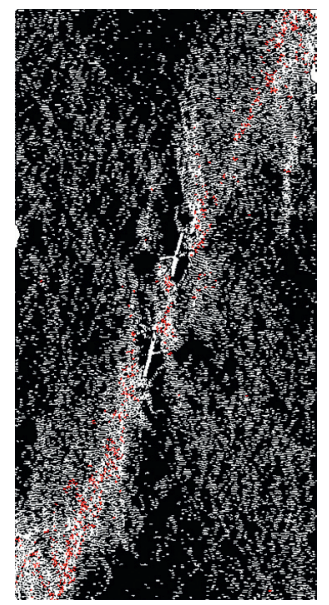

(b)

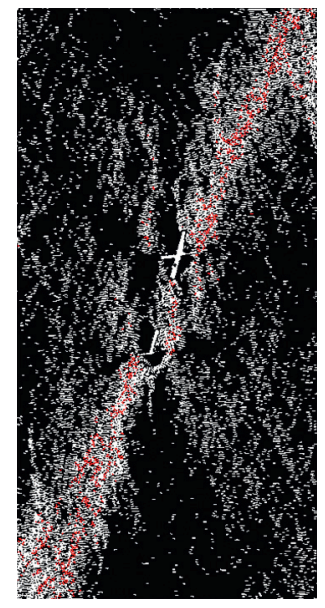

(c)

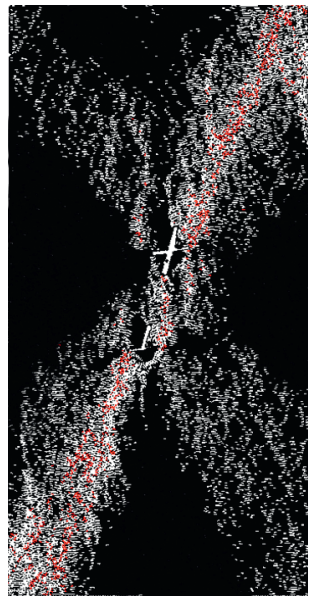

(d)

FIGURE 16: Crack distribution in rocks for different ratios of uniaxial compressive strength to tensile strength: (a) UCS/TS = 13.93, (b) UCS/ $\mathrm{TS}=11.72$, (c) UCS/TS $=9.79$, and (d) UCS $/ \mathrm{TS}=7.82$.

TABLE 8: Total number of cracks and the numbers of tensile and shear cracks for different ratios of uniaxial compressive strength to tensile strength.

\begin{tabular}{lccccc}
\hline UCS/TS & Crack & Crack_tension & Crack_shear & Crack_shear/crack & Crack_tension/crack \\
\hline 13.93 & 51714 & 50965 & 749 & 0.014 & 0.986 \\
11.72 & 41616 & 40692 & 924 & 0.022 & 0.978 \\
9.79 & 32011 & 31030 & 981 & 0.031 & 0.969 \\
7.82 & 24547 & 23105 & 1442 & 0.059 & 0.941 \\
\hline
\end{tabular}

materials in terms of mechanical properties. It is known from engineering practice, and the compression-tension ratio is not related to the nature of the rock material itself. However, it can be seen from the actual test results that the compression and tension ratios of different species of rocks are varied, and even for the same kind of rock, the compression and tension ratios may be diverse, which is related to the nature of the rock itself. So, it is necessary to explore the relationship between the compression-tension ratio and the properties of the rock material itself and the effect on crack propagation. It is extremely difficult to achieve the same rock material with different tension/compression ratios through experiments. However, the FJM model is superior in that it can change the microparameters to adjust 


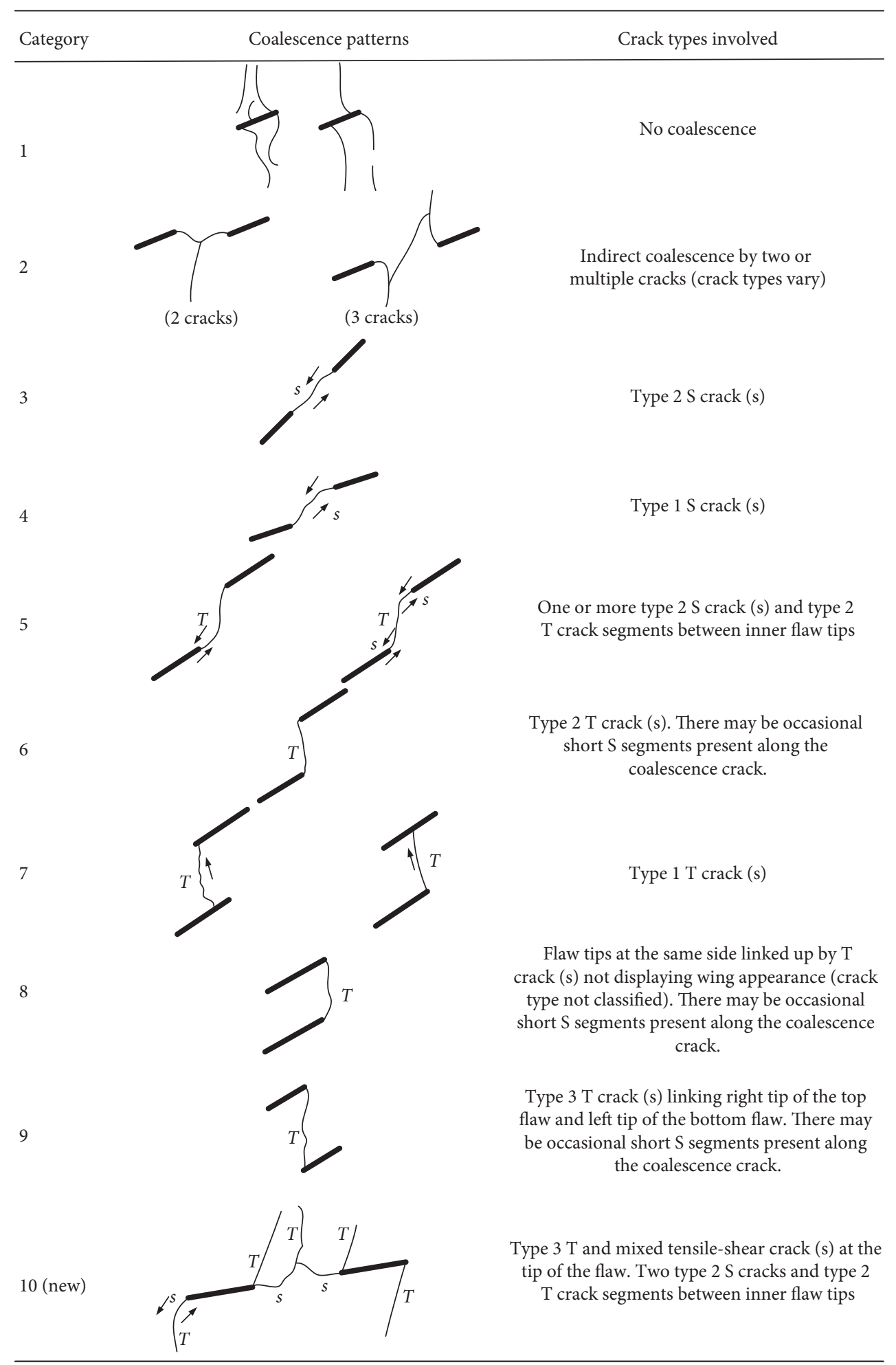

FIGURE 17: Ten crack coalescence categories obtained in the present experiments.

the UCS/TS ratio without changing the other properties. Interparticle tensile strength $\left(\sigma_{b}\right)$ and particle cohesion strength $\left(c_{b}\right)$ have significant effects on the UCS/TS ratio. Therefore, different UCS/TS ratios can be obtained by altering $\sigma_{b}$ and $c_{b}$. To maintain the consistency of specimens, the UCS was kept constant, while only the TS was altered. We selected the model for the following flaw geometric parameters: $k=0.67$ and $\alpha=45^{\circ}$; the TS was changed to 2.01 , 
$2.39,2.86$, and $3.58 \mathrm{MPa}$, corresponding to the UCS/TS ratios of $13.93,11.72,9.79$, and 7.82 , respectively.

The distribution of tensile and shear cracks in the rocks during the final failure for different UCS/TS ratios is shown in Figure 16, whereas the total number of cracks and the numbers of tensile and shear cracks are provided in Table 8. When the UCS/TS ratio is 13.93 , the tension and the cracks are uniformly distributed throughout the rock mass (Figure 16(a)). The ratio of tensile to shear cracks is $70: 1$. When the UCS/TS ratio drops to 11.72 (Figure 16(b)), shear cracks are distributed along the connection direction of the two primary flaws, while tensile cracks are reduced to $97.8 \%$ of the total cracks. When the UCS/TS ratio drops to 9.79 (Figure 16(c)), the proportion of tensile cracks decreases further, whereas the proportion of shear cracks continues to increase. When the UCS/TS drops to 7.82 (Figure 16(d)), shear cracks account for $5.9 \%$ of the total cracks, whereas tensile cracks only account for $4.1 \%$. The total number of cracks is reduced with decreasing UCS/TS ratio. This indicates that the tensile strength of bonded particle has a major effect on the level of rock cracking and is consistent with the existing research results that a high will lead to a large ratio of tensile to shear cracks, which corresponds to a large UCS/TS ratio [36].

5.2. Crack Coalescence Categories. In addition to those nine crack coalescence categories described in the introduction, we also identify a new category of crack coalescence in our experiments, and these coalescence categories are summarized (Figure 17) according to the classification in the literature [3]. Based on experimental results, this study has suggested that the crack coalescence category is distinct from previous studies possibly due to the length of rock bridge being smaller than the length of the flaw. This is because the length of rock bridge is usually larger than the length of the flaw [44]. However, when $k=0.57$, the length of the rock bridge is $18 \mathrm{~mm}$, while the length of the main flaw is $12 \mathrm{~mm}$, where we identify crack coalescence in category $X$.

\section{Conclusions}

In order to study the pattern of crack extension and the form of crack coalescence in natural rocks subjected to loading that more closely, laboratory experiments were conducted. Numerical simulations of PFC based on the FJM model were also carried out, and the simulation results showed that the FJM model can capture the crack evolution process well during the experiments, revealing that the FJM model can be a powerful tool in the study of crack evolution. Additionally, this model can simulate rock materials with differing UCS/ TS ratios and then evaluate the effects of differing UCS/TS ratios on rock cracks and failure modes. The following conclusions have been obtained from the study:

(1) In both experimental and numerical simulation results, it can be found that the type III tensile cracks sprout first at the tip of the prefabricated flaws. The joint persistency affects rock failure modes, and the failure mode shifts from tensile splitting failure to shear failure with increasing joint persistency.

(2) A new crack coalescence pattern was discovered, where crack coalescence occurs between the main and minor flaws.

(3) The generation of hybrid crack and the initiation position of first cracks are both affected by $\alpha$. The hybrid crack begins to occur when $\alpha>45^{\circ}$. With the increasing joint persistency of the rocks, the crack initiation stress decreased and the coalescence stress increased.

(4) The angle between wing crack (initiated at the tip of the main flaw) and the primary flaw increases with the increasing $k$.

(5) With increasing UCS/TS ratio, the number of shear cracks decreases and the number of tensile cracks and the total number of cracks increases, while the degree of rock failure becomes more severe than low UCS/TS ratio $[5,45,46]$.

At present, the research on the fracture mechanism of three-dimensional built-in fracture is still in the exploration stage, and the experimental research has achieved certain results. However, the fracture test of three-dimensional fracture itself is a complex process with many uncertainties and many influencing factors. Only through continuous research can the theory of three-dimensional fracture be improved continuously.

\section{Data Availability}

The data used to support the findings of this study are available from the corresponding author upon request.

\section{Conflicts of Interest}

The authors declare that they have no conflicts of interest.

\section{Acknowledgments}

This work was supported by the National Natural Science Foundation of China (52034007 and 52074263) and the National Key Research and Development (2017YFC0603001).

\section{References}

[1] R. H. C. Wong and K. T. Chau, "Crack coalescence in a rocklike material containing two cracks," International Journal of Rock Mechanics and Mining Sciences, vol. 35, no. 2, pp. 147-164, 1998.

[2] M. Sagong and A. Bobet, "Coalescence of multiple flaws in a rock-model material in uniaxial compression," International Journal of Rock Mechanics and Mining Sciences, vol. 39, pp. 229-241, 2002.

[3] L. N. Y. Wong and H. H. Einstein, "Crack coalescence in MGC marble: part 1. Macroscopic oi," Rock Mechanics and Rock Engineering, vol. 42, no. 3, pp. 475-511, 2008.

[4] C. H. Park and A. Bobet, "Crack coalescence in specimens with open and closed flaws: a comparison," International 
Journal of Rock Mechanics and Mining Sciences, vol. 46, no. 5, pp. 819-829, 2009.

[5] A. Bobet and H. H. Einstein, "Fracture coalescence in rocktype materials under uniaxial and biaxial compression," International Journal of Rock Mechanics and Mining Sciences, vol. 35, no. 7, pp. 863-888, 1998.

[6] E. Hoek and Z. T. Bieniawski, "Brittle fracture propagation in rock under compression," International Journal of Fracture Mechanics, vol. 1, no. 3, pp. 137-155, 1965.

[7] D. Huang, D. Gu, C. Yang, R. Huang, and G. Fu, "Investigation on mechanical behaviors of sandstone with two preexisting flaws under triaxial compression," Rock Mechanics and Rock Engineering, vol. 49, no. 2, pp. 375-399, 2015.

[8] N. A. Al-Shayea, "Crack propagation trajectories for rocks under mixed mode I-II fracture," Engineering Geology, vol. 81, no. 1, pp. 84-97, 2005.

[9] D. Q. Dan and H. Konietzky, "Numerical simulations and interpretations of Brazilian tensile tests on transversely isotropic rocks," International Journal of Rock Mechanics and Mining Sciences, vol. 71, pp. 53-63, 2014.

[10] H. Haeri, K. Shahriar, M. F. Marji, and P. Moarefvand, "Experimental and numerical study of crack propagation and coalescence in pre-cracked rock-like disks," International Journal of Rock Mechanics and Mining Sciences, vol. 67, pp. 20-28, 2014.

[11] X.-P. Zhou, X.-B. Gu, and Y.-T. Wang, "Numerical simulations of propagation, bifurcation and coalescence of cracks in rocks," International Journal of Rock Mechanics and Mining Sciences, vol. 80, pp. 241-254, 2015.

[12] G. Xu, C. He, Z. Chen, and A. Su, "Transverse isotropy of phyllite under Brazilian tests: laboratory testing and numerical simulations," Rock Mechanics and Rock Engineering, vol. 51, no. 4, pp. 1111-1135, 2017.

[13] P. Wang, M. Cai, and F. Ren, "Anisotropy and directionality of tensile behaviours of a jointed rock mass subjected to numerical Brazilian tests," Tunnelling and Underground Space Technology, vol. 73, pp. 139-153, 2018.

[14] X.-X. Yang and W.-G. Qiao, "Numerical investigation of the shear behavior of granite materials containing discontinuous joints by utilizing the flat-joint model," Computers and Geotechnics, vol. 104, pp. 69-80, 2018.

[15] R. P. Janeiro and H. H. Einstein, "Experimental study of the cracking behavior of specimens containing inclusions (under uniaxial compression)," International Journal of Fracture, vol. 164, no. 1, pp. 83-102, 2010.

[16] S.-Q. Yang, P. G. Ranjith, H. W. Jing, W. L. Tian, and Y. Ju, "An experimental investigation on thermal damage and failure mechanical behavior of granite after exposure to different high temperature treatments," Geothermics, vol. 65, pp. 180-197, 2017.

[17] D. Li, Q. Zhu, Z. Zhou, X. Li, and P. G. Ranjith, "Fracture analysis of marble specimens with a hole under uniaxial compression by digital image correlation," Engineering Fracture Mechanics, vol. 183, pp. 109-124, 2017.

[18] F. Erdogan and G. C. Sih, "On the crack extension in plates under plane loading and transverse shear," Journal of Basic Engineering, vol. 85, no. 4, p. 527, 1963.

[19] S. K. Maiti and R. A. Smith, "Comparison of the criteria for mixed mode brittle fracture based on the preinstability stressstrain field," International Journal of Fracture, vol. 23, no. 4, pp. 281-295, 1983.

[20] X. M. Kong, N. Schlüter, and W. Dahl, "Effect of triaxial stress on mixed-mode fracture," Engineering Fracture Mechanics, vol. 52, no. 2, pp. 379-388, 1995.
[21] A. Bobet and H. H. Einstein, "Fracture coalescence in rock material under uniaxial and biaxial loading," Key Engineering Materials, vol. 183-187, pp. 809-814, 1996.

[22] B. Antonio, Fracture Coalescence in Rock Materials: Experimental Observations and Numerical Predictions, Massachusetts Institute of Technology, Cambridge, MA, USA, 1997.

[23] J. R. Rice, "A path independent integral and the approximate analysis of strain concentration by notches and cracks," Journal of Applied Mechanics, vol. 35, no. 2, pp. 379-386, 1967.

[24] M. Hussain, S. Pu, and J. Underwood, "Strain energy release rate for a crack under combined mode I and mode II," in S560-EB Fracture Analysis: Proceedings of the 1973 National Symposium on Fracture Mechanics, Part II, G, pp. 2-28, ASTM International, West Conshohocken, PA, USA, 1973.

[25] G. C. Sih, "Strain-energy-density factor applied to mixed mode crack problems," International Journal of Fracture, vol. 10, no. 3, pp. 305-321, 1974.

[26] P. S. Theocaris and N. P. Andrianopoulos, "The T-criterion applied to ductile fracture," International Journal of Fracture, vol. 20, no. 20, pp. R125-R130, 1982.

[27] P. S. Theocaris and N. P. Andrianopoulos, "The mises elasticplastic boundary as the core region in fracture criteria," Engineering Fracture Mechanics, vol. 16, no. 3, pp. 425-432, 1982.

[28] P. S. Theocaris, G. A. Kardomateas, and N. P. Andrianopoulos, "Experimental study of the T -criterion in ductile fractures," Engineering Fracture Mechanics, vol. 17, no. 5, pp. 439-447, 1983.

[29] A. A. Wells, "Application of fracture mechanics at and beyond general yield," British Welding Journal, vol. 10, pp. 563-570, 1963.

[30] O. Reyes and H. H. Einstein, "Failure mechanisms of fractured rock: a fracture coalescence model," in Proceedings of the 1991 ISRM Congress, Aachen, Germany, 1991.

[31] X.-P. Zhang and L. N. Y. Wong, "Cracking processes in rocklike material containing a single flaw under uniaxial compression: a numerical study based on parallel bonded-particle model approach," Rock Mechanics and Rock Engineering, vol. 45, pp. 711-737, 2011.

[32] A. Manouchehrian and M. F. Marji, "Numerical analysis of confinement effect on crack propagation mechanism from a flaw in a pre-cracked rock under compression," Acta Mechanica Sinica, vol. 28, no. 5, pp. 1389-1397, 2012.

[33] X.-P. Zhang and L. N. Y. Wong, "Crack initiation, propagation and coalescence in rock-like material containing two flaws: a numerical study based on bonded-particle model approach," Rock Mechanics and Rock Engineering, vol. 46, no. 5, pp. 1001-1021, 2013.

[34] M. Bahaaddini, G. Sharrock, and B. K. Hebblewhite, "Numerical investigation of the effect of joint geometrical parameters on the mechanical properties of a non-persistent jointed rock mass under uniaxial compression," Computers and Geotechnics, vol. 49, pp. 206-225, 2013.

[35] J. Yoon, "Application of experimental design and optimization to PFC model calibration in uniaxial compression simulation," International Journal of Rock Mechanics and Mining Sciences, vol. 44, no. 6, pp. 871-889, 2007.

[36] S. Wu and X. Xu, "A study of three intrinsic problems of the classic discrete element method using flat-joint model," Rock Mechanics and Rock Engineering, vol. 49, no. 5, pp. 1813-1830, 2015.

[37] H. Li and L. N. Y. Wong, "Influence of flaw inclination angle and loading condition on crack initiation and propagation," 
International Journal of Solids and Structures, vol. 49, no. 18, pp. 2482-2499, 2012.

[38] W. F. Brace, B. W. Paulding Jr., and C. H. Scholz, "Dilatancy in the fracture of crystalline rocks," Journal of Geophysical Research, vol. 71, no. 16, pp. 3939-3953, 1966.

[39] Z. T. Bieniawski, "Mechanism of brittle fracture of rock: part I-theory of the fracture process," International Journal of Rock Mechanics and Mining Sciences \& Geomechanics Abstracts, vol. 4, pp. 395-406, 1967.

[40] D. J. Holcomb and L. S. Costin, "Damage in brittle materials: experimental methods," in Proceedings of the 10th U.S. National Congress of Applied Mechanics, J. P. Lamb, Ed., Austin, TX, USA, June 1987.

[41] C. D. Martin, The strength of massive Lac du Bonnet granite around underground openings, Ph.D. thesis, University of Manitoba, Winnipeg, Canada, 1993.

[42] D. A. Lockner, J. D. Byerlee, V. Kuksenko, and A. Ponomarev, "Observations of quasistatic fault growth from acoustic emissions," in Fault Mechanics and Transport Properties of Rocks, B. Evans and T.-f. Wong, Eds., Academic Press, Cambridge, MA, USA, pp. 3-31, 1992.

[43] C. D. Martin and N. A. Chandler, "The progressive fracture of Lac du Bonnet granite," The progressive fracture of Lac du Bonnet granite, vol. 31, pp. 643-659, 1994.

[44] H. Lee and S. Jeon, "An experimental and numerical study of fracture coalescence in pre-cracked specimens under uniaxial compression," International Journal of Solids and Structures, vol. 48, no. 6, pp. 979-999, 2011.

[45] M. A. K. Shafique and M. K. Khan, "Analysis of mixed mode crack initiation angles under various loading conditions," Engineering Fracture Mechanics, no. 67, pp. 397-419, 2000.

[46] D. O. Potyondy and P. A. Cundall, "A bonded-particle model for rock," International Journal of Rock Mechanics and Mining Sciences, vol. 41, no. 8, pp. 1329-1364, 2004. 